\title{
Improvement of rheological and filtration characteristics of water-based drilling fluids using naturally derived henna leaf and hibiscus leaf extracts
}

\author{
Abdul R. Ismail ${ }^{1,2} \cdot$ Noorul M. N. A. Mohd ${ }^{1,2,3} \cdot$ Nurul F. Basir $^{1,2} \cdot$ Jeffrey O. Oseh $^{1,2,4} \mathbb{D}^{\circ} \cdot$ Issham Ismail $^{1,2}$. \\ Shafeeg O. Blkoor ${ }^{1,2}$
}

Received: 14 April 2020 / Accepted: 16 September 2020 / Published online: 29 September 2020

(c) The Author(s) 2020

\begin{abstract}
Biodegradable additives are required to minimize the environmental hazards from drilling fluid wastes. This study explores the feasibility of the applications of henna leaf extracts (HLE) and hibiscus leaf extracts (HBLE) as ecological benign products in water-based drilling fluids (WBDFs). Rheological and filtration characterizations were carried out on the WBDFs to detect the effects of different concentrations $(1,2,10,20,30$, and $40 \mathrm{~g})$ of these plant extracts at 78 and $300{ }^{\circ} \mathrm{F}$. The results of 1 and $2 \mathrm{~g}$ of the plant extracts were compared with those of low-viscosity polyanionic cellulose (PAC LV). Compatibility test was carried out using $25 \mathrm{~g} / \mathrm{L}$ of the green additives on base fluid (A-0), and the swelling rate of sodium bentonite in distilled water was also considered using 1,10 , and $20 \mathrm{~g}$ of the green additives. The findings showed that HLE and HBLE significantly reduced the filtrate loss between $62 \%$ and $67 \%$ and between $64 \%$ and $76 \%$, respectively, and improved the rheological characteristics of the WBDF system between 10 and $40 \mathrm{~g}$. PAC LV showed a greater effect on the rheological properties than the green additives in equal amounts ( 1 and $2 \mathrm{~g}$ ), but it exhibited flat high and progressive gels which can lead to mechanical pipe sticking. The test data also showed that the inclusion of HLE and HBLE in the WBDF demonstrated larger impact on the mud cake than PAC LV. The cake thickness of the WBDF was reduced in the following order: 30-32\% (by HLE), 32-33\% (by HBLE), and 24-27\% (by PAC LV). This interprets the outstanding filtration characteristics of green additives. Further, compatibility test data confirmed that the green additives are compatible with the other base fluid additives and the swelling behavior of sodium bentonite verified that the green plants are effective in inhibiting bentonite swelling. Here, the Henna extracts displayed higher inhibition property than the Hibiscus product. Notwithstanding, both products showed excellent inhibition property and a strong viscosity enhancing effect on the WBDF system.
\end{abstract}

Keywords Filtrate loss volume $\cdot$ Henna leaf extracts $\cdot$ Hibiscus leaf extracts $\cdot$ Rheological properties

Noorul M. N. A. Mohd

anam@utm.my

1 Department of Petroleum Engineering, School of Chemical and Energy Engineering, Universiti Teknologi Malaysia, 81310 Johor Bahru, Malaysia

2 Malaysia Petroleum Resources Corporation Institute for Oil and Gas (MPRC-UTM), Universiti Teknologi Malaysia, 81310 Johor Bahru, Malaysia

3 Advanced Membrane Technology Research Center (AMTEC), Universiti Teknologi Malaysia, 81310 Johor Bahru, Malaysia

4 Department of Chemical and Petroleum Engineering, College of Engineering, Afe Babalola University, P.M.B. 5454, Ado-Ekiti, Ekiti State, Nigeria

$\begin{array}{ll}\text { Abbreviations } \\ \text { 10 s GS } & \text { Initial gel } \\ 10 \text { min GS } & \text { 10 minutes gel } \\ \text { AHR } & \text { After hot rolling } \\ \text { API FL } & \text { Filtrate loss volume at } 100 \text { psi pressure and } \\ & 78^{\circ} \mathrm{F} \\ \text { API MCT } & \text { Mud cake thickness at } 100 \text { psi pressure and } \\ & 78^{\circ} \mathrm{F} \\ \text { API } & \text { American petroleum institute } \\ \text { AV } & \text { Apparent viscosity } \\ \text { BHR } & \text { Before hot rolling } \\ \text { CMC } & \text { Carboxyl methylcellulose } \\ \text { FL } & \text { Filtrate loss volume } \\ \text { GS } & \text { Gel strength } \\ \text { HBLE } & \text { Hibiscus leaf extracts } \\ \text { HLE } & \text { Henna leaf extracts }\end{array}$




$\begin{array}{ll}\text { HPHT FL } & \text { Filtrate loss volume at 500 psi pressure and } \\ & 30{ }^{\circ} \mathrm{F} \\ \text { HPHT MCT } & \begin{array}{l}\text { Mud cake thickness at 500 psi pressure and } \\ 300{ }^{\circ} \mathrm{F}\end{array} \\ & \text { High-pressure high-temperature } \\ \text { HPHT } & \text { Potassium chloride } \\ \text { KCl } & \text { Lost circulation materials } \\ \text { LCMs } & \text { Mud cake thickness } \\ \text { MCT } & \text { Mud weight } \\ \text { MW } & \text { Sodium hydroxide } \\ \text { NaOH } & \text { Oil-based drilling fluids } \\ \text { OBDFs } & \text { Oxygen scavenger } \\ \text { OX-SCAV } & \text { Low-viscosity polyanionic cellulose } \\ \text { PAC LV } & \text { Partially hydrolyzed polyacrylamide } \\ \text { PHPA } & \text { Plastic viscosity } \\ \text { PV } & \text { Rate of penetration } \\ \text { ROP } & \text { Water-based drilling fluids } \\ \text { WBDFs } & \text { Yield point } \\ \text { YP } & \end{array}$

\section{Introduction}

It is often difficult to locate and develop new petroleum fields in challenging drilling environments, such as deeper offshores, geothermal wells, or high-pressure high-temperature (HPHT) environments. Improving field techniques, including multipurpose, cost-saving, environmentally accepted, and more efficient drilling fluids, have made the drillings of longer-reach wells, deeper wells, and more complicated wells possible. Such fluids, however, should be built to work efficiently and not to cause damage to the formation (Zhong et al. 2019; Oseh et al. 2019a, b). Oil-based drilling fluids (OBDFs) and water-based drilling fluids (WBDFs) are the most widely used drilling fluids for hydrocarbon productions. OBDFs have been the drilling fluid of choice in unforgiving and complex drilling formations for many years, largely for their high-temperature resistance up to $500{ }^{\circ} \mathrm{F}$, high lubricity, superb salt tolerance, high rate of penetration (ROP), and efficient carrying capacity of cuttings (Amani et al. 2012; Nanthagopal et al. 2019). However, environmental regulations have increased the restrictions on their applications since the 1980s because of their harmful drilling wastes (Nanthagopal et al. 2019; Oseh et al. 2019c, d). Also, high expense and negative impacts on the well cementing pose some drawbacks on applying OBDFs because of weak adhesion between the casing and the formation (Sayindla et al. 2017). The use of WBDFs is an attractive alternative from an economic and environmental perspective. Nonetheless, it also has some flaws, such as low lubricity, low ROP, and increased contact with the formation of hydrophilic clay, which causes wellbore instability due to problems with dispersion and swelling of the clay (Ismail et al. 2015; Xu et al. 2018). Therefore, different additives for WBDFs are constantly being developed to achieve OBDF-like properties (Sayindla et al. 2017; Fujii 2017).

Bentonite-based WBDF system is still the most preferred fluid system in the field to drill oil and gas wells (Choo and Bai 2015). The basic design criteria for WBDFs applied in HPHT wells include Wyoming bentonite (high purity and quality sodium montmorillonite) at low concentrations and fluid additives with only one primary function (Choo and Bai 2015). In freshwater or low salt-water fluids, bentonite is added to provide viscosity required to suspend drilled cuttings and barite (Caenn et al. 2017). At higher salinities, bentonite no longer hydrates and at high temperatures exceeding $300{ }^{\circ} \mathrm{F}$, the clays in the fluid need special attention owing to a gelation process (Kelessidis 2017; Darjani et al. 2017, 2019). The gelation leads to undue fluid viscosity, especially for high-density drilling fluids, and result in increased filtrate flux and unstable wellbore (Saboori et al. 2018). Maintaining wellbore stability is an important function of drilling fluids, which is strongly affected by rheology, filtration control, and filter cake thickness (Saboori et al. 2018; Oseh et al. 2020a, b). The intrusion of water into permeable formation weakens the stability of the wellbore and causes serious drilling problems, such as tight holes, pipe stuck, and wellbore collapse, which hampers the drilling program severely (Saboori et al. 2018; Oseh et al. 2020a, b). Therefore, rheology and filtration control properties of WBDFs are two critical parameters that are optimized to achieve a successful drilling operation.

The common practice in the petroleum industry is to use viscosity modifiers, fluid loss control additives, or even lost circulation materials (LCMs), such as bentonite, barite, graphite, and calcium carbonate to formulate conventional WBDF system. Quite often, commercial macro-polymers, such as partially hydrolyzed polyacrylamide (PHPA), starch, guar gum, xanthan gum, cellulose derivatives, and carboxyl methylcellulose (CMC), are also incorporated to improve the overall properties of the WBDF system (Choo and Bai 2015). This is because these products form hydrogen bonds with water molecules. The bond formation increases the strength of the intermolecular forces that govern the viscosity of the liquid phase (Oseh et al. 2019c, d). Also, polymer, such as polyanionic cellulose (PAC) acts as a fluid loss reducing agent which minimizes the flow of fluid to form a thin cake with low permeability (Luz et al. 2017). It can also improve the viscosity of the drilling fluids depending on its molecular weight and chemical structure (Al-Hameedi et al. 2020). These additives are large size diameter chemicals and are chemically processed. Also, they are non-biodegradable and can present severe harm when exposed to living things. Therefore, the need for ecologically benign materials that will contribute to the regulation of mud properties with an increase in performance without causing environmental hazards could be essential. World concerns about environmental protection from the adverse effects of non-biodegradable 
products and chemicals are increasing daily. Such concerns are pushing the petroleum industry in the production of safe, cost-effective, sustainable, and environmentally benign drilling fluids from naturally occurring plant extracts.

Recently, the development of locally derived Henna Leaf Extracts (HLE) as a viscosity modifier (Oseh et al. 2019a), filtration control agent (Moslemizadeh et al. 2015), and clay swelling inhibitor (Moslemizadeh et al. 2016) has caught the attention of researchers. HLE is a naturally occurring plant that came from the family of Lythraceae. It is mostly grown in dry tropical and subtropical zones, including Morocco, Yemen, Iran, Nigeria, Iraq, India, Sri Lanka, Afghanistan, Pakistan, and Egypt (Gozubuyuk et al. 2014; Oseh et al. 2018). It is a low-cost and environmentally friendly material that is readily soluble in water. It can act as anti-corrosion in various metallic mediums (Ostovari et al. 2009).

Hibiscus leaf extracts (HBLE) are another natural product that originated from the Malvaceae family. It is a flowering, perennial, woody ornamental shrub widely found in the tropical region. It has been well proven to be medicinal in different studies. It provides an effective antidote to skin rashes and allergies (Obi et al. 1998; Sharada et al. 2012). Sharada et al. (2012) reported that HBLE showed antioxidant properties by producing flavonoids and other phenolic compounds that minimized the harmful effects of UV (ultraviolet) radiation. Fresh hibiscus leaves are typically composed of about $85 \%$ moisture content. Others of their components are ash, fat, phosphorus, fiber, calcium, and thiamine. The chemical components of the leaves are isoamyl alcohol, anisaldehyde, methanol, benzyl alcohol, malic acid, niacin, isopropyl alcohol, and 3-methyl-i-butanol (Choo and Bai 2015). Hibiscus leaves are highly economical, devoid of side effects, biocompatible, biodegradable, renewable, and environmentally friendly (Obi et al. 1998; Sharada et al. 2012). The green HBLE as a viscosifier and filtrate loss reducing agent in drilling operations have not been reported in open literature, and this study, therefore, presents its effect in a complex WBDF system.

Typically, industrial-grade low-viscosity PAC (PAC LV) is a very popular chemical used in the field to prevent water leakage into the drilled formation and its characteristics are well documented in several studies. PAC LV is an anionic cellulose ether, soluble in water, and is synthesized using alkali-catalyzed process. It has a high degree of substitution and purity. It also has exceptional features, comprising excellent salt resistance, good temperature stability (stable up to $300{ }^{\circ} \mathrm{F}$ ), and strong antibacterial activity (Thomas 1982; Balestrini et al. 2009). However, being a chemical additive, the indiscriminate discharge of its effluents into the environments can be harmful to human health and aquatic lives.

There are rather few studies in open literature regarding the effect of locally derived green additives on the rheological and filtration characterizations of WBDFs (Al-Sehaibani 2002; Sharada et al. 2012; Abdollahi and Shadizadeh 2012; Wei 2013; Omotioma and Ejikeme 2014; Gozubuyuk et al. 2014; Samaravati et al. 2014; Moslemizadeh et al. 2015, 2016). Considering economic, sustainability, and environmental factors, as well as the need to promote the local content initiative, development of naturally derived plant-based polymers, such as HLE and HBLE, might improve the rheological and filtration characteristics of WBDFs. These plant extracts are low-costs, biodegradable, non-toxic, and ecologically benign and could be effective in enhancing the physicochemical properties of the complex WBDF system. Therefore, in this study, locally derived green additives (HLE and HBLE) were processed and applied to enhance the rheological and filtration characteristics of the WBDF system. To determine their suitability as filtrate loss control agents and possible applications in the field, their rheological and filtration properties were compared with those of the commonly used industrial-grade PAC LV at $78^{\circ} \mathrm{F}$ and a high temperature of $300{ }^{\circ} \mathrm{F}$. Furthermore, the compatibility of these products with some common WBDF additives was assessed and their swelling inhibiting impact of sodium bentonite was evaluated.

\section{Experimental}

\section{Materials}

The chemicals applied in this study are potassium chloride $(\mathrm{KCl})$, caustic soda $(\mathrm{NaOH})$, bentonite, PHPA, oxygen scavenger (OX-SCAV), barite, sodium chloride $(\mathrm{NaCl})$, and PAC LV. The industrial-grade PAC LV served as filtration control and viscosifier. The green leaf extracts of henna and hibiscus were supplied by a local commercial store (Johor, Malaysia), and they are shown in Fig. 1.

\section{Formulation of drilling fluids}

The green leaves (HLE and HBLE) were dried separately in an oven for $48 \mathrm{~h}$ at $160{ }^{\circ} \mathrm{F}$ to remove moisture. The dried green leaves were crushed into powder form using a grinder. They were filtered to their finest form to reduce the solute content and were stored in a sealed plastic bag at room temperature before their applicability in the WBDF system. The WBDF was formulated in ascending order according to Table 1 with four different concentrations $(10,20,30$, and $40 \mathrm{~g}$ ) of each of HLE and HBLE products. The formulation of the fluids shown in Table 1 was carried out to study the effects of the green additives (HLE and HBLE) in the complex WBDF system. To evaluate the filtration control performance of these green additives and compare them with a commercial PAC LV, two lower concentrations (1.0 and

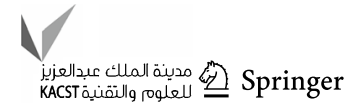


$2.0 \mathrm{~g}$ ) of each of the HLE, HBLE, and PAC LV were added into the WBDF after the inclusion of barite. A representation of this formulation is depicted in Table 2 .

\section{General testing program of drilling fluids}

The properties of the formulated fluid samples were examined using the recommended American Petroleum Institute (API) testing standards (API RP 13B-1 2017). For the tests of mud properties, different fluid samples were formulated. Tests were conducted on the fluids before hot rolling (BHR) and after hot rolling (AHR) at $78^{\circ} \mathrm{F}$ and $300{ }^{\circ} \mathrm{F}$, respectively. The fluids were hot-rolled at $300{ }^{\circ} \mathrm{F}$ for $960 \mathrm{~min}$ in an aging steel cell using a model-35 Fann viscometer. The $\mathrm{pH}$ of different concentrations $(10,20,30$, and $40 \mathrm{~g})$ of the green additives was determined using the $\mathrm{pH}$ meter at $78^{\circ} \mathrm{F}$ to evaluate the sensitivity of the $\mathrm{pH}$ of the green additives on the aqueous (WBDF) system. The mud weight (MW) was measured using the fluid balance at $78^{\circ} \mathrm{F}$ and $300{ }^{\circ} \mathrm{F}$.
Equations (1-3) were used to calculate the plastic viscosity ( $\mathrm{PV}$ in $\mathrm{cP}$ ), yield point ( $\mathrm{YP}$ in $\left.\mathrm{lb} / 100 \mathrm{ft}^{2}\right)$, and apparent viscosity (AV in $\mathrm{cP}$ ). The gel strength (GS) was measured by shearing the fluid at $10 \mathrm{~s}$ (initial GS) and then letting it rest for $10 \mathrm{~s}$. The maximum shear stress value at $3 \mathrm{rpm}$ was recorded after the rest time as initial GS. The same procedure was followed for the 10 minutes (10 min) GS, but in this case, the samples were rested for $10 \mathrm{~min}$. After the samples were hot-rolled at $300^{\circ} \mathrm{F}$ for a continuous $16 \mathrm{~h}$, the same procedures were used for all the measurements of rheological properties. The API fluid loss (API FL) investigation was executed at $78^{\circ} \mathrm{F}$ and 100 psi pressure after a continuous 30-min test period and thereafter the API mud cake thickness (API MCT) was measured using a Fann supplied ruler. HPHT filter press was introduced to test for the HPHT FL at $300^{\circ} \mathrm{F}$ (heating temperature) at a differential pressure of $500 \mathrm{psi}$, and the resulting MCT was measured again. All the tests were done thrice, and the average readings were registered.
Fig. 1 Leaf extracts and powder after processing $\mathbf{a}$ henna and $\mathbf{b}$ hibiscus

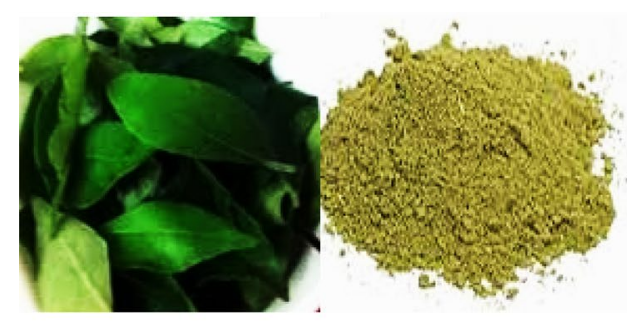

(a)
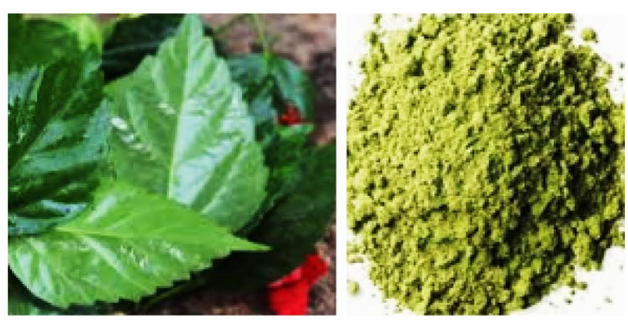

(b)
Table 1 Components of WBDF, HLE, and HBLE drilling fluids

Table 2 Components of WBDF with 1.0 and $2.0 \mathrm{~g}$ each of HLE, HBLE, and PAC LV

\begin{tabular}{lllll}
\hline Component & Function & WBDF & HLE & HBLE \\
\hline Water (ml) & Base fluid & 320 & 320 & 320 \\
Bentonite $(\mathrm{g})$ & Viscosifier and filtrate loss reducer & 25 & 25 & 25 \\
$\mathrm{NaOH}(\mathrm{g})$ & pH control & 0.2 & 0.2 & 0.2 \\
PHPA (g) & Filtrate loss reducer and viscosifier & 1.0 & 1.0 & 1.0 \\
OX-SCAV (g) & Corrosion inhibitor & 1.5 & 1.5 & 1.5 \\
KCl (g) & Clay swelling inhibitor & 25 & 25 & 25 \\
Barite (g) & Weighing agent & 125 & 125 & 125 \\
WBDF + HLE & Viscosifier and filtration control & - & $10,20,30$, and & - \\
& & & $40 \mathrm{~g}$ & 10,20, \\
WBDF + HBLE & Viscosifier and filtration control & - & - & 30, and \\
& & & & $40 \mathrm{~g}$ \\
\hline
\end{tabular}

\begin{tabular}{|c|c|c|c|c|c|c|}
\hline \multirow[t]{2}{*}{ Fluid } & \multicolumn{2}{|c|}{ PAC LV } & \multicolumn{2}{|l|}{ HLE } & \multicolumn{2}{|c|}{ HBLE } \\
\hline & $1.0 \mathrm{~g}$ & $\overline{2.0 \mathrm{~g}}$ & $1.0 \mathrm{~g}$ & $\overline{2.0 \mathrm{~g}}$ & $1.0 \mathrm{~g}$ & $\overline{2.0 \mathrm{~g}}$ \\
\hline WBDF & - & - & - & - & - & - \\
\hline $\mathrm{WBDF}+\mathrm{PAC}$ LV & 1.0 & 2.0 & - & - & - & - \\
\hline WBDF + HLE & - & - & 1.0 & 2.0 & - & - \\
\hline WBDF + HBLE & - & - & - & - & 1.0 & 2.0 \\
\hline
\end{tabular}


$A V=\theta 600 / 2$

$P V=\theta 600-\theta 300$

$Y P=0.511(\theta 300-P V)$

\section{Compatibility and permeability tests}

Another important factor that is always considered before introducing any additive for drilling formulation is the compatibility of such additive with other fluid additives. Hence, the compatibility test was conducted to inspect the compatibility between the common WBDF additives and the evaluated green additives (HLE and HBLE). This aspect of the investigation was accomplished by adding $25 \mathrm{~g} / \mathrm{L}$ of the green additives (HLE and HBLE) into test fluid A-0 (base fluid) (Table 3). The fluids were subjected to an aging cell in a dynamic rolling oven for $4 \mathrm{~h}$ at $221^{\circ} \mathrm{F}$, and the changes in their dial readings and filtrate losses were measured before and after introducing the green additives. After the measurement of the filtration properties, the permeability of the mud cake was determined at this HPHT condition. The investigation was carried out by the filtration rate through the mud cake based on Darcy's law according to the reports of Elochukwu et al. (2017). Darcy's law is defined by Eq. (4).

$\frac{d v}{d t}=\frac{K A \Delta P}{\mu h}$

where $d v / d t$ is the filtration rate, $K$ is the cake permeability, $A$ is the area of cross-section, $\Delta P$ is the pressure differential, $\mu$ is the viscosity of the fluid, and $h$ is the mud cake thickness achieved from Eqs. (5 and 6).

$h=\frac{V_{f}}{A\left(\frac{f_{s c}}{f_{s m}}-1\right)}$

where $f_{s c}$ is the volume fraction of deposited solids in the mud cake, $f_{s m}$ is the volume fraction of the solids in drilling fluids, and $t$ is the time of the filtration experiment. It can be noted that the cross section of the mud cake was kept constant at $31.2 \mathrm{~cm}^{2}$ and the filtrate viscosity $\left(V_{f}\right)$ was evaluated at a differential pressure of $500 \mathrm{psi}$.
$V_{f}=A \sqrt{\frac{2 K \Delta P}{\mu}\left(\frac{f_{s c}}{f_{s m}}-1\right)} \times \sqrt{t}$

\section{Dynamic linear swelling tests}

To examine the influence of the green additives on the swelling behavior of sodium bentonite, different concentrations $(1,10$, and $20 \mathrm{~g})$ of HLE and HBLE solutions were prepared. Afterward, a dynamic swelling test was carried out by compressing $10 \mathrm{~g}$ of sodium bentonite powder in distilled water under a pressure of $5900 \mathrm{psi}(40 \mathrm{MPa})$ for $24 \mathrm{~h}$ using hydraulic compactor according to the works of Moslemizadeh et al. (2015) and Darjani et al. $(2017 ; 2019)$ with some changes. The tests were conducted at a temperature of $78^{\circ} \mathrm{F}$ and atmospheric pressure conditions.

\section{Results and discussion}

\section{Effects of HLE and HBLE on the rheological and filtration properties of WBDF}

The effects of different concentrations $(10,20,30$, and $40 \mathrm{~g})$ of the locally-derived green additives in a conventional WBDF system are tabulated in Tables 4 and 5 at $78^{\circ} \mathrm{F}$ and $300^{\circ} \mathrm{F}$, while the $\mathrm{pH}$ of different concentrations of the green additives is presented in Fig. 2.

\section{pH observation}

Drilling fluid additives are developed to be mixed with water with a pH level from 8.5 to 10 for the needed chemical reaction to occur and to provide a proper yield (Gamal et al. 2019). After mixing and preparing the WBDF system, the mud $\mathrm{pH}$ was measured at $78^{\circ} \mathrm{F}$ and the results are presented in Fig. 2. According to Fig. 2, there were changes in the mud $\mathrm{pH}$ with the inclusion of HLE and HBLE products at different concentrations. For the HLE product, the $\mathrm{pH}$ of the WBDF system at 9.3 decreased with an increase in HLE concentration (between 4.86 and 4.72), while the reverse was the case when HBLE (between 5.84 and 7.47) was introduced into the WBDF system. The data of the $\mathrm{pH}$ of
Table 3 Designed compatibility tests fluids

\begin{tabular}{ll}
\hline Test fluids & Compositions \\
\hline $\mathrm{A}-0=$ Base fluid & $50 \mathrm{~g} / \mathrm{L} \mathrm{KCl}+100 \mathrm{~g} / \mathrm{L}+\mathrm{NaCl}+7.0 \mathrm{~g} / \mathrm{L} \mathrm{PAC} \mathrm{LV}+2.0 \mathrm{~g} / \mathrm{L} \mathrm{PHPA}$ \\
$\mathrm{A}-1=\mathrm{A}-0+25 \mathrm{~g} / \mathrm{L} \mathrm{HLE}$ & $320 \mathrm{ml}$ distilled water $+50 \mathrm{~g} / \mathrm{L} \mathrm{KCl}+100 \mathrm{~g} / \mathrm{L}+\mathrm{NaCl}+7.0 \mathrm{~g} / \mathrm{L}$ \\
& PAC LV $+2.0 \mathrm{~g} / \mathrm{L} \mathrm{PHPA}+25 \mathrm{~g} \mathrm{HBLE}$ \\
$\mathrm{A}-2=\mathrm{A}-0+25 \mathrm{~g} / \mathrm{L} \mathrm{HBLE}$ & $320 \mathrm{ml}$ distilled water $+50 \mathrm{~g} / \mathrm{L} \mathrm{KCl}+100 \mathrm{~g} / \mathrm{L}+\mathrm{NaCl}+7.0 \mathrm{~g} / \mathrm{L}$ \\
& PAC LV $+2.0 \mathrm{~g} / \mathrm{L} \mathrm{PHPA}+25 \mathrm{~g} / \mathrm{L} \mathrm{HBLE}$ \\
\hline
\end{tabular}


Table 4 The measured mud properties at different concentrations
Table 5 The measured mud properties at different concentrations

\begin{tabular}{|c|c|c|c|c|c|c|c|c|c|c|}
\hline \multicolumn{11}{|c|}{ Before hot rolling tests $\left(78^{\circ} \mathrm{F}\right)$} \\
\hline \multirow[t]{2}{*}{ Properties } & \multirow[t]{2}{*}{ Units } & \multirow[t]{2}{*}{ WBDM } & \multicolumn{4}{|c|}{$\operatorname{HLE}(\mathrm{g})$} & \multicolumn{4}{|c|}{$\operatorname{HBLE}(\mathrm{g})$} \\
\hline & & & 10 & 20 & 30 & 40 & 10 & 20 & 30 & 40 \\
\hline MW & ppg & 11.5 & 11.5 & 11.4 & 11.4 & 11.4 & 11.4 & 11.3 & 11.3 & 11.3 \\
\hline AV & $\mathrm{cP}$ & 23 & 71 & 96 & 86 & 101 & 78 & 132 & 152 & 165 \\
\hline PV & $\mathrm{cP}$ & 12 & 52 & 64 & 56 & 66 & 53 & 75 & 87 & 70 \\
\hline YP & $\mathrm{lb} / 100 \mathrm{ft}^{2}$ & 22 & 38 & 65 & 60 & 71 & 51 & 114 & 130 & 190 \\
\hline Initial GS & $\mathrm{lb} / 100 \mathrm{ft}^{2}$ & 6.0 & 16 & 20 & 18 & 24 & 17 & 36 & 41 & 53 \\
\hline $10 \min \mathrm{GS}$ & $\mathrm{lb} / 100 \mathrm{ft}^{2}$ & 9.0 & 20 & 25 & 21 & 29 & 26 & 50 & 61 & 72 \\
\hline API FL & $\mathrm{ml}$ & 9.7 & 3.7 & 3.4 & 3.7 & 3.2 & 3.5 & 3.1 & 2.3 & 2.6 \\
\hline API MCT & $\mathrm{mm}$ & 3.77 & 1.90 & 1.75 & 1.86 & 1.64 & 1.78 & 1.68 & 1.44 & 1.54 \\
\hline
\end{tabular}

Fig. $2 \mathrm{pH}$ of different concentrations of HLE and HBLE in WBDF system

\begin{tabular}{|c|c|c|c|c|c|c|c|c|c|c|}
\hline \multicolumn{11}{|c|}{ After hot rolling tests $\left(300^{\circ} \mathrm{F}\right)$} \\
\hline \multirow[t]{2}{*}{ Properties } & \multirow[t]{2}{*}{ Units } & \multirow[t]{2}{*}{ WBDM } & \multicolumn{4}{|c|}{ HLE (g) } & \multicolumn{4}{|c|}{$\operatorname{HBLE}(\mathrm{g})$} \\
\hline & & & 10 & 20 & 30 & 40 & 10 & 20 & 30 & 40 \\
\hline MW & ppg & 11.4 & 11.4 & 11.4 & 11.4 & 11.4 & 11.3 & 11.3 & 11.3 & 11.3 \\
\hline AV & $\mathrm{cP}$ & 21 & 39 & 51 & 50 & 71 & 77 & 120 & 127 & 140 \\
\hline PV & $\mathrm{cP}$ & 11 & 23 & 29 & 27 & 45 & 41 & 70 & 75 & 66 \\
\hline YP & $\mathrm{lb} / 100 \mathrm{ft}^{2}$ & 20 & 33 & 44 & 45 & 52 & 73 & 100 & 104 & 148 \\
\hline Initial GS & $\mathrm{lb} / 100 \mathrm{ft}^{2}$ & 5.0 & 12 & 15 & 17 & 20 & 14 & 23 & 36 & 40 \\
\hline $10 \mathrm{~min}$ GS & $\mathrm{lb} / 100 \mathrm{ft}^{2}$ & 8.0 & 15 & 17 & 20 & 23 & 24 & 30 & 41 & 52 \\
\hline HPHT FL & $\mathrm{ml}$ & 10.1 & 6.2 & 5.1 & 5.9 & 4.5 & 5.6 & 3.4 & 3.1 & 3.7 \\
\hline НРНТ МСТ & $\mathrm{mm}$ & 3.86 & 2.55 & 1.92 & 2.16 & 1.72 & 1.77 & 1.71 & 1.62 & 1.73 \\
\hline
\end{tabular}

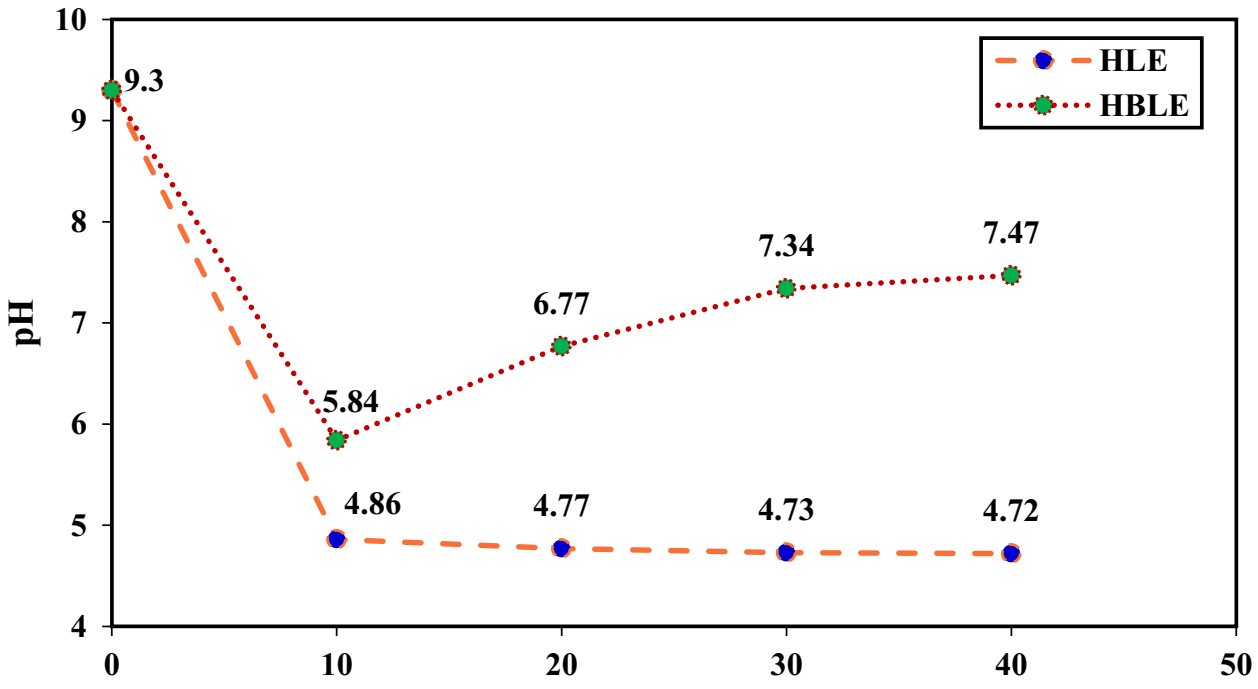

the HLE product corroborated the reports of Moslemizadeh et al. (2015) in that Henna leaf extracts are acidic in aqueous solution, while Hibiscus leaf is slightly acidic between the $\mathrm{pH}$ of 5.5 and 7.5 (Gamal et al. 2019). It is generally believed that Henna extracts solution in water removes the hydrogen atoms from the chemical structure of its constituents, resulting in a consequent reduction of the $\mathrm{pH}$ of the solution (Gamal et al. 2019). 


\section{Mud weight}

The weight of a drilling fluid is a key parameter in drilling operations. The fluid MW is an important factor in drilling operations and its output. The majority of problems faced during rotary drillings are related to the weights of drilling fluids (Fattah and Lashin 2016). To effectively determine the influence of HLE and HBLE on the fluid loss, fluid cake thickness, and formation damage, the MW is the first property to investigate. Typically, how stable is a fluid is governed by its uniformity after aging for a long time. As presented in Tables 4 and 5, there is no considerable variation in the MW of the fluids. The drilling fluids showed a very narrow range of variation. However, after hot rolling experiments at $300{ }^{\circ} \mathrm{F}$, the MW of the fluids reduced slightly which is not high enough to result in damage to the formation (Fattah and Lashin 2016).

\section{Apparent viscosity}

Tables 4 and 5 illustrate that the AV of the different fluid systems containing plant extracts (HLE and HBLE) was increased significantly with an increase in concentration over that of the WBDF system. This increase can be detrimental to drilling operations in terms of lost circulation, excess pump power requirement, equivalent circulating density, etc. According to both Tables 4 and 5, the plant extracts need a lower range of concentration to achieve an effective removal of drilled particles and successful drillings without causing harm to the formation. Observation at these tables showed that with $30 \mathrm{~g} \mathrm{HLE}$, the AV values were reduced to $86 \mathrm{cP}$ from $96 \mathrm{cP}$ (Table 4). For $20 \mathrm{~g}$, it reduced to $50 \mathrm{cP}$ from $51 \mathrm{cP}$ (Table 5) but started increasing again after the $30 \mathrm{~g}$ concentration. A similar trend of reduction in $\mathrm{AV}$ was noticed in the AV of the HBLE from $20 \mathrm{~g}$ to $30 \mathrm{~g}$ after aging (Table 5). The AV of the HBLE exhibited higher values as compared to those of HLE at both temperature conditions. The increase in AV of the WBDF with HLE and HBLE at $10 \mathrm{~g}$ is about thrice greater than that of the WBDF at $78^{\circ} \mathrm{F}$ and even quadrupled with $20 \mathrm{~g}$ HLE and sixfold with $20 \mathrm{~g}$ HBLE (Table 4). At a higher temperature of $300^{\circ} \mathrm{F}$, the AV of the WBDF reduced slightly compared to that of HLE which exhibited higher reductions. Also, the HLE samples from 10 to $40 \mathrm{~g}$ showed a higher drop in AV than those of HBLE samples. This result implies that the molecules of henna are more sensitive to high temperatures than those of HBLE and the additives that make up the WBDF.

\section{Plastic viscosity}

The PV is an indicator of the viscosity of the high shear rate and is dependent on the liquid phase viscosity and the amount of solids in a liquid. The PV is improved by adding solid additives and can be further enhanced by solids, such as clays, which are swelled by taking in water (Annis and Smith 1996). The rheometric PV data presented in Tables 4 and 5 revealed that as the HLE and HBLE increase in concentration, a larger PV is seen in all cases over that of the WBDF system. For the PV of the base fluid, the water was easily adsorbed by sodium bentonite and it swelled quickly. This led to achieving the separation of individual unit layers and a resultant increase in the PV (Moslemizadeh et al. 2015). Also, the interaction of other additives in the base fluid such as PHPA with bentonite can induce bridging which yielded the solution viscosity (Oseh et al. 2019a, b, c). A higher viscosifying effect for both HLE and HBLE is confirmed at both $78^{\circ} \mathrm{F}$ and $300^{\circ} \mathrm{F}$. This feature can be linked to the presence of hydrogen bonds in both HLE and HBLE that interacted with the hydrogen ions of water molecules. It can also be linked to the branched molecular chains of the HLE and HBLE products (Moslemizadeh et al. 2016).

According to Table 4, the inclusion of HLE and HBLE has great increasing effects in the PV of the WBDF with increasing concentration. This same effect can be observed after the aging tests (Table 5). Nonetheless, the observed decrease in the AV of HLE from 20 to $30 \mathrm{~g}$ was also observed in the PV of the HLE at the same concentrations. A similar trend of results in terms of PV also occurred in the HBLE fluid samples from 30 to $40 \mathrm{~g}$ at both temperatures. The inclusion of $40 \mathrm{~g}$ concentration of HBLE in the WBDF system reduced the PV by $19.5 \%$ from 30 to $40 \mathrm{~g}$ (Table 4 ) and $12 \%$ from 75 to $66 \mathrm{cP}$ (Table 5). The decrement of the $\mathrm{AV}$ and PV values of the two plant extracts fluid samples can be related to the reduction of the fluids gelation caused by a decrease in the interaction of the molecules (Oseh et al. $2020 \mathrm{~b}, \mathrm{c})$. This action can also be due to a decrease in the adherence between the hydrogen ions of water molecules and the hydrogen bonds present in the plant extracts (Moslemizadeh et al. 2015). The HBLE fluid samples have a larger PV than those of HLE at the two temperature conditions considered. These data reported in Tables 4 and 5 suggest a great viscosifying power of the plant extracts. However, their potential benefits in a WBDF system could depend on their concentrations and other additives in the fluid.

\section{Yield point}

Everything causing changes in the viscosity of the low shear rate is expressed in the YP. The YP indicates that clay strata are susceptible to joining up and creating a flocculated structure (Annis and Smith 1996). The tabularized depiction of the YP data presented in Tables 4 and 5 as calculated by filling in the dial-reading values into Eq. (3) indicates that the inclusion of HLE and HBLE changes the YP of the WBDF. There were significant enhancements in the YP with increasing concentration of the green additives. However, at $30 \mathrm{~g}$

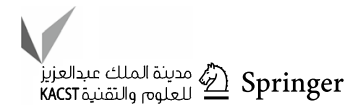


HLE, the YP was reduced to $60 \mathrm{lb} / 100 \mathrm{ft}^{2}$ from $65 \mathrm{lb} / 100 \mathrm{ft}^{2}$ of $20 \mathrm{~g}$ HLE concentration. As observed in both tables, the YP of the HBLE at all concentrations is larger than those of the HLE. The application of HLE and HBLE as additives for drilling fluids might promote local content expansion but their introduction into WBDFs should be painstakingly considered by studying the behavior of the additives that will make up the fluid, especially if higher concentrations are to be used. According to the results depicted in Table 5, an increase in temperature up to $300^{\circ} \mathrm{F}$ significantly affects the YP of the fluids in a decreasing manner. Nevertheless, at 10 and $20 \mathrm{~g}$ of HBLE, the YP values $\left(73 \mathrm{lb} / 100 \mathrm{ft}^{2}\right.$ for $10 \mathrm{~g}$ and $124 \mathrm{lb} / 100 \mathrm{ft}^{2}$ for $20 \mathrm{~g}$ ) increased after being subjected to aging treatment over $\left(51 \mathrm{lb} / 100 \mathrm{ft}^{2}\right.$ for $10 \mathrm{~g}$ and $114 \mathrm{lb} / 100 \mathrm{ft}^{2}$ for $20 \mathrm{~g}$ ) without heat treatments. The HBLE demonstrated the greater enhancement of the YP than the HLE as it does in the PV of the WBDF but could lead to poor circulation rate, decreased ROP, borehole washout, and increased frictional pressure losses.

\section{Gel strength}

GS is a measurement of shearing stress needed to start a fluid flow immobile for a long time. It is something that facilitates or prevents contact between clay layers and, therefore, will either increase or decrease the gelling propensity of a dispersion (Luz et al. 2017). The influence of concentration of the locally derived HLE and HBLE on the initial and 10 min gels of the WBDFs is depicted in Tables 4 and 5. In the deficiency of HLE and HBLE in the WBDFs, Tables 4 and 5 portray 6.0 and $5.0 \mathrm{lb} / 100 \mathrm{ft}^{2}$ for the initial gel and 9.0 and $8.0 \mathrm{lb} / 100 \mathrm{ft}^{2}$ for the $10 \mathrm{~min}$ gel, respectively. A very narrow range of variation occurred in both the initial and 10 min gels at both temperatures, indicating low flat gels which are desirable for drillings as it will not lead to stuck pipe (Luz et al. 2017). In the inclusion of different concentrations of HLE and HBLE in the WBDF, both the initial and 10 min gels were increased with an increasing concentration at 78 and $300{ }^{\circ} \mathrm{F}$. At different concentrations of the green additives, the variations in the gels of HLE are less compared to those of HBLE at both temperature conditions. This behavior is similar to the results of $\mathrm{AV}, \mathrm{PV}$, and YP reported earlier. In general, HBLE exhibited the highest gels and the variations in both gels (10 s and $10 \mathrm{~min}$ ) are so large (exceeding $10 \mathrm{lb} / 100 \mathrm{ft}^{2}$ ) that it can cause differential pipe sticking while drilling.

For the results of all the rheological parameters (AV, PV, YP, and GS), the parameters were decreased at the higher temperature of $300^{\circ} \mathrm{F}$. The weakening of molecular attraction forces, which bind liquid molecules together caused this behavior. Consequently, the distance between the molecules increased and the fluid's interaction became reduced (Fattah and Lashin 2016). The rheological data shown in Tables 4 and 5 also demonstrated that the impact of the plant extracts (HLE and HBLE) on the AV, PV, YP, and GS of the WBDFs was gelling with an increasing concentration. This behavior can again be elucidated in the form that the HLE and HBLE unite on the bentonite clay platelets and enhance the attractive forces between the platelets (Aftab et al. 2016). It is, therefore, suggested that a lower concentration of the plant extracts must be used to obtain the desired rheological parameters within the API recommended protocols. Expounding further, given the need to protect the formation from fracture and damage, prevent borehole washout, and avoid excessive frictional pressure losses, a concentration of $10 \mathrm{~g}$ of both plant extracts on the rheological data (Tables 4 and 5) can be considered as the optimum concentration for the effective drilling operation.

\section{Filtration control parameters}

One of the key properties of drilling fluids is the filtration rate. Strong filtration levels increase the thickness of the fluid, leading to operational problems like pipe sticking and high torque and drag (Al-Hameedi et al. 2019a, b). The measured filtrate losses represented in Tables 4 and 5 verified that the base fluid system with the plant extracts demonstrated a significant reduction in filtrate loss under the API and HPHT conditions with increasing concentration. However, there is an exception to the reduction at the concentrations of $30 \mathrm{~g}$ HLE and $40 \mathrm{~g}$ HBLE, where the decreasing trend of the filtrate loss does not hold. Clear and significant changes were seen in both the API and HPHT FL of the WBDFs with the inclusion of the green additives. The general trend of the decrement in the API FL of WBDF with HLE is ranged between 61.9 and $67.0 \%$ and that of HLBE is ranged between 64.0 and $76.3 \%$ against $9.7 \mathrm{ml}$ of WBDF. At HPHT condition, this trend showed a small margin of increment to $10.1 \mathrm{ml}$ using the WBDF alone but decreased to the range between 38.6 and $55.4 \%$ with the inclusion of HLE and between 44.6 and $69.3 \%$ for the incorporation of HBLE.

The HBLE showed the more improved capacity of decreasing the loss of filtrate of the base fluid system at both temperature conditions than the HLE at all concentrations. This is because HBLE contains humic acid which makes the aqueous medium soluble. The soluble HBLE in WBDF was a deflocculant due to the creation of negative ions $(-\mathrm{OH})$ groups by interacting with bentonite to strengthen the sealing of the mud cake on the wellbore (Sharada et al. 2012). From the study of Oseh et al. (2019a), HLE has superb filtrate loss sealing property at high concentrations due to the high mobility of hydrogen ions that strengthens the sealing capacity of the WBDF. According to Tables 4 and 5, the relatively high volume loss of filtrate of WBDF in comparison with HLE and HBLE suggests that the $\mathrm{KCl}$ presence needed for the 
inhibition of clay swelling and hydration led to a higher volume of filtrate loss of the WBDF than it does in the plant products (Zhong et al. 2011).

The higher the failure of filtrate loss control agents, the thicker the mud cake thickness (MCT). As revealed by Tables 4 and 5, there are appreciable variations in the API and HPHT MCT of the WBDFs with different concentrations of the plant extracts. These results illustrated that WBDFs formulated with the plant extracts exhibited a high decreasing trend of cake thickness under API and bottomhole conditions with an increasing concentration of $20 \mathrm{~g}$ and $30 \mathrm{~g}$ for HLE and HBLE, respectively. It can also be seen from these tables that at $30 \mathrm{~g}$ HLE, both the API and HPHT MCT are higher than the values of $20 \mathrm{~g}$ HLE product. From the rheological and filtration data trend, similar behavior was also observed for $30 \mathrm{~g}$ HLE and $40 \mathrm{~g}$ HBLE products. Looking at the data presented in Tables 4 and $5,10 \mathrm{~g}$ of both the HLE and HBLE appears to be the optimum concentration of reducing the loss of drilling fluid as it displayed filtrate loss and cake thickness less than $4.0 \mathrm{ml}$ and $2.0 \mathrm{~mm}$, respectively, under the API conditions.

\section{The rheological characteristics of WBDFs investigated with PAC LV and plant extracts}

According to the preceding results recounted in Tables 4 and 5, the higher concentrations of the green additives used to enhance the properties of the WBDF demonstrated gelation characteristics of the fluids, which require deflocculant to control the properties. Therefore, to have a meaningful comparison between these green additives and PAC LV for possible improvement in the rheology and filtration properties of the base fluid system, lower concentrations (1.0 and $2.0 \mathrm{~g}$ ) of each of HLE, HBLE, and PAC LV were compared in this section. The test data of the mud properties at 78 and $300{ }^{\circ} \mathrm{F}$ are presented in Figs. 3, 4, 5, 6, 7, and 8 .

Beginning with the results of the MW shown in Fig. 3, the 1.0 and $2.0 \mathrm{~g}$ concentrations of HLE and HBLE showed no
Fig. 3 Mud weight of drilling fluids

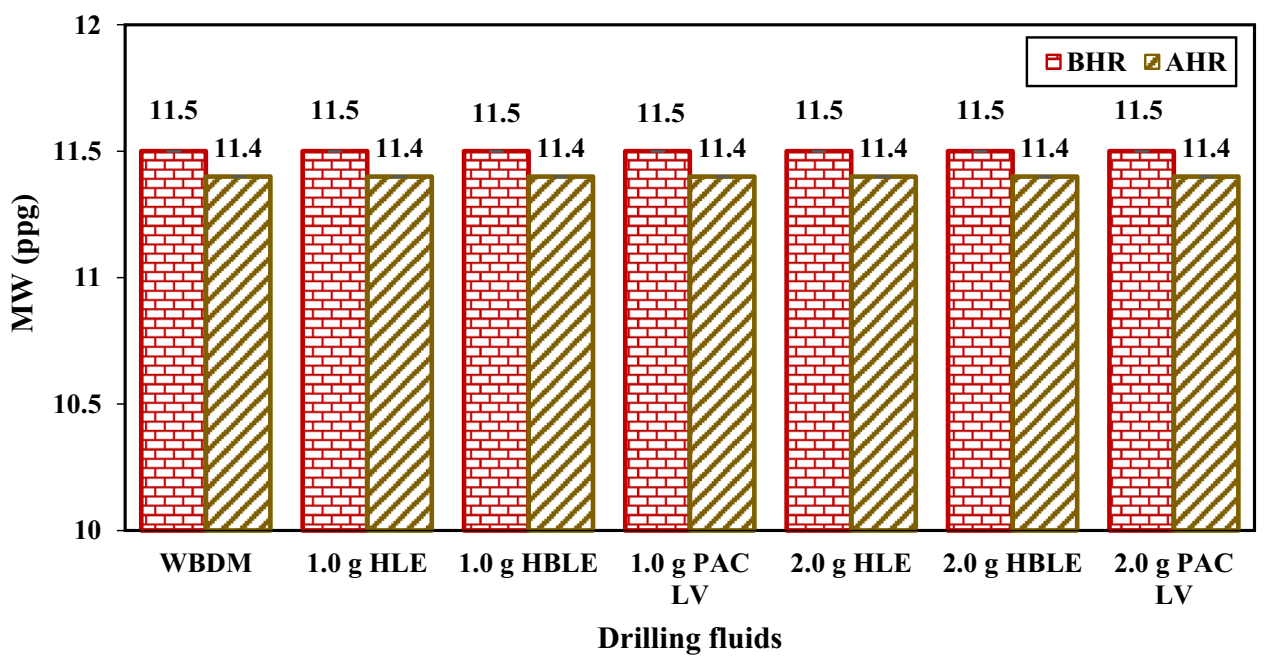

Fig. 4 Apparent viscosity of drilling fluids

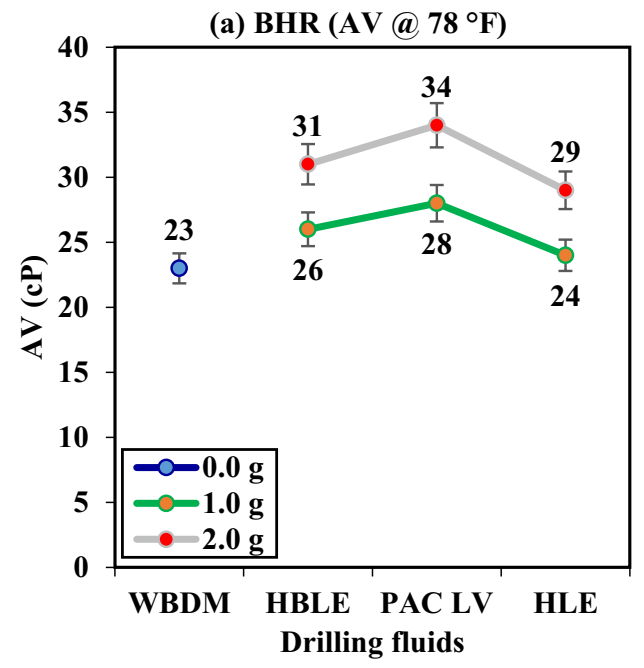

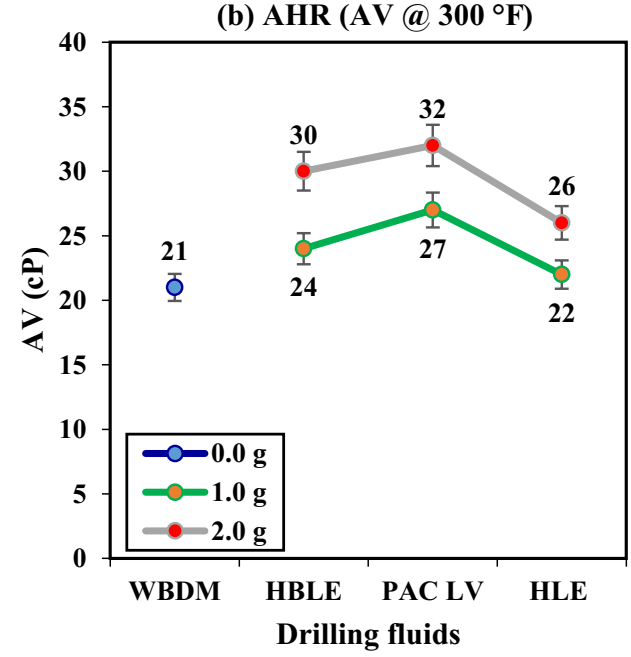

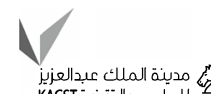

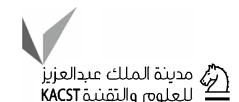


Fig. 5 Plastic viscosity of drilling fluids

Fig. 6 Yield point of drilling fluids

Fig. 7 Initial gel strength of drilling fluids (a) BHR (PV@ $\left.97^{\circ} \mathrm{F}\right)$
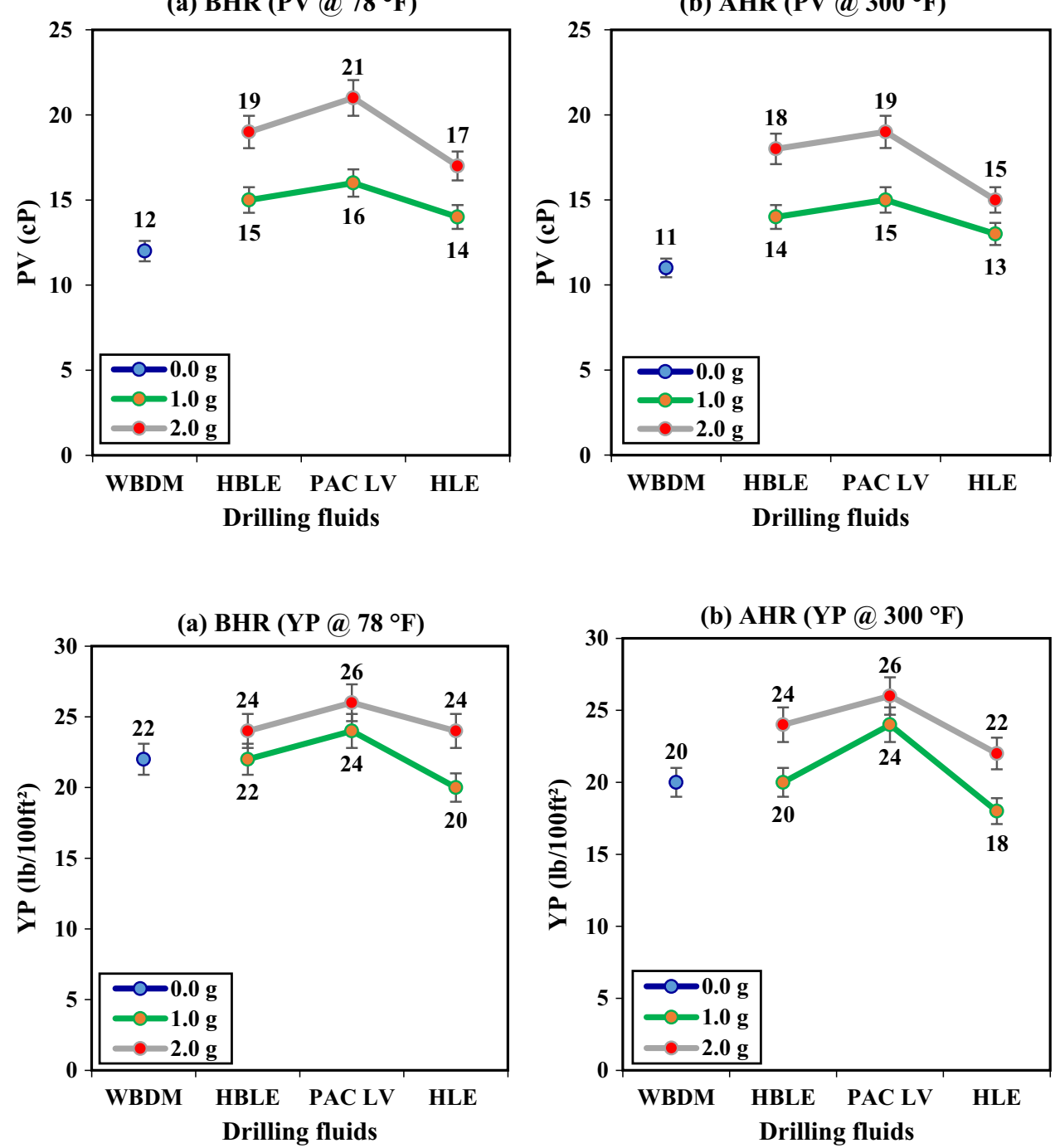

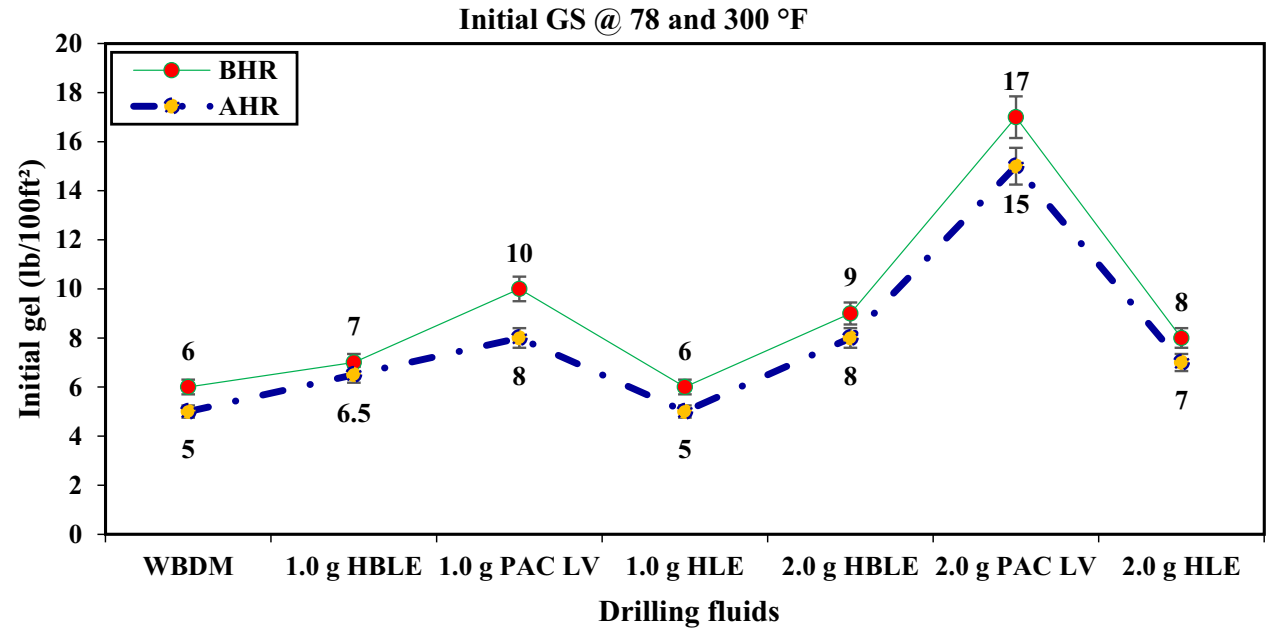


Fig. 8 Gel 10 of drilling fluids

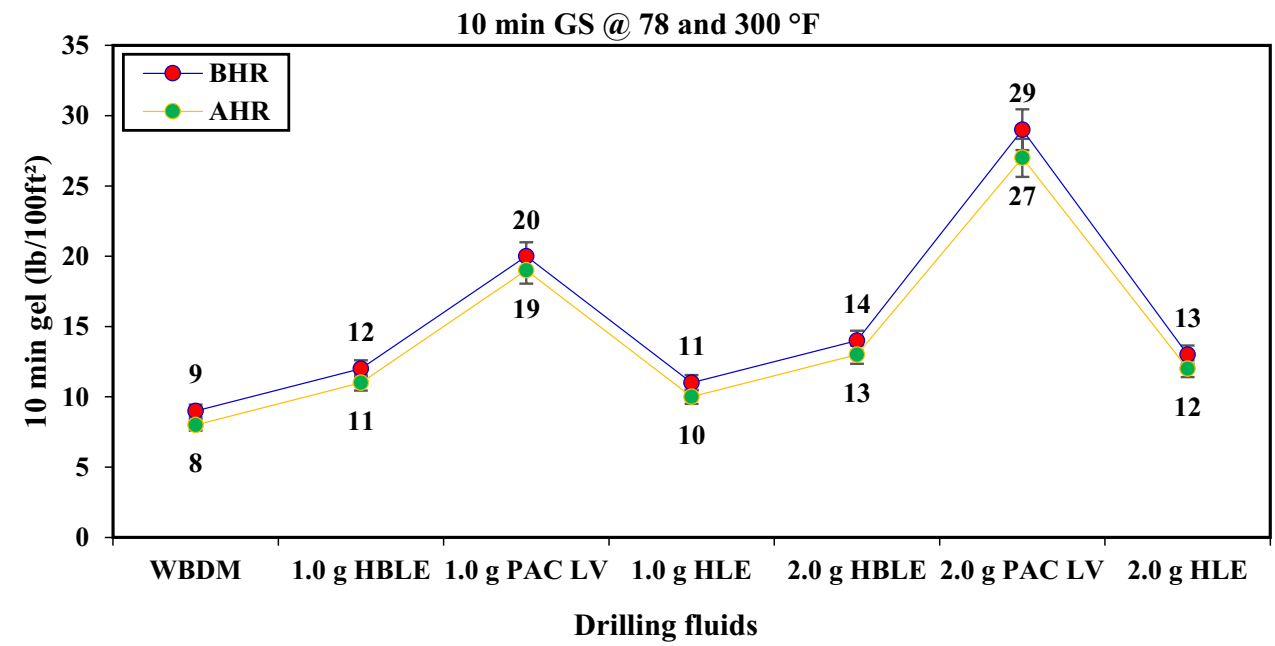

variation in the MW of all the mud systems as it remained constant at $11.5 \mathrm{ppg}$ and $14 \mathrm{ppg}$ before and after hot rolling measurements, respectively. After the aging process (AHR at $300{ }^{\circ} \mathrm{F}$ ), the $\mathrm{MW}$ of the drilling fluids had an insignificant effect. The motive behind this negligible effect was due to the fluid's sensitivity to the higher temperature. It can also be due to the formation of foams in the fluid after aging, as observed in the course of the experiments. Therefore, antifoaming agents can be suggested to preserve the weight of the fluid if necessary as the drop in the MW is only a little fraction (Iheagwara 2015). For the rheological parameters, the locally derived HLE and HBLE inclusion increased the AV (Fig. 4), the PV (Fig. 5), and the YP (Fig. 6) of the WBDF systems with increasing concentration at both 78 and $300{ }^{\circ} \mathrm{F}$. The increase was more with the concentrations of HBLE than those of HLE. A higher increase in these properties occurred in the WBDFs containing PAC LV more than those of the plant extracts at both temperature conditions. However, these green additives (HLE and HBLE) exhibited strong rheological effects on the WBDF system at the two concentrations of 1.0 and $2.0 \mathrm{~g}$. The values of these fluids will not require extra pressure to pump and circulate. Also, there were no traces of aggregates in these mud systems indicating that the plant extracts are well dispersed and soluble in the mud (Mozaffari et al. 2015, 2017). These results confirm the applicability of these plant extracts as rheological modifiers at concentrations of 1.0 and 2.0 during a typical drilling situation.

Describing further, these plant extracts displayed an excellent suspension ability of drilled particles since the variation of the GS between the $10 \mathrm{~s}$ and $10 \mathrm{~min}$ is not large (not more than $5.0 \mathrm{lb} / 100 \mathrm{ft}^{2}$ ) for both the HLE and HBLE (Figs. 7 and 8). These gels, that are those of the WBDF, HLE, and HBLE, indicate encouraging suspension property and the ability of the gels to break easily when drillings are restarted after a prolonged static condition (Oseh et al. 2020a, b). For PAC LV, it displayed a negative effect on both the $10 \mathrm{~s}$ and $10 \mathrm{~min}$ gels, especially the $2.0 \mathrm{~g}$ concentration and the difference between these gels exceeds $10 \mathrm{lb} / 100 \mathrm{ft}^{2}$. This could need extra pump pressure to break the gels when changing from non-flow to flow conditions, which in turn can adversely affect pump efficiency and cause fractures in poor formations (Ismail et al. 2019). It, therefore, holds that, if higher concentrations of PAC LV are introduced into the complex WBDF system as per this study, it might result in flocculation (Oseh et al. 2019c, d).

Additives of PAC are strong chemicals that have been applied in different field applications in drilling operations for many years to increase rheological properties and decrease filtrate loss. In the field, an excess concentration of PAC LV which is equal to the laboratory scale range between 1.2 and $1.8 \mathrm{~g}$ per $1000 \mathrm{ml}$ (Al-Hameedi et al. 2020) is normally introduced. In this study, $1.0 \mathrm{~g}$ per $350 \mathrm{ml}$ and $2.0 \mathrm{~g}$ per $350 \mathrm{ml}$ of PAC LV were added to the WBDF system to have identical concentrations with the plant extracts. In this manner, the rheological parameters were exploited with the inclusion of PAC LV concentrations, as shown in Figs. 4, 5, 6,7 , and 8. Referring again to the rheological behavior of the plant extracts, the results shown in Figs. 4, 5, 6, 7, and 8 and those in the previous section displayed in Tables 4 and 5 verified that HBLE exhibited higher rheological values than HLE product. HLE is a deflocculant as reported by Moslemizadeh et al. (2015) and Oseh et al. (2019a) and can be used to control the fluid's rheological properties, especially the GS and YP which is because of the changes that occur in its composition when it interacts with molecules of water. As the lower concentrations (1.0 and $2.0 \mathrm{~g}$ ) of HLE got into contact with the molecules of water, hydrogen ions were detached from its structure and negative ions were formed. The positive edge of the clay layers (sodium bentonite) in the fluid became neutralized by the negative ions resulting in a decrease in the GS and YP. However, HLE is inefficient

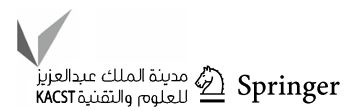


when it comes to reducing the viscosity of the fluid (Moslemizadeh et al. 2015).

\section{The filtration characteristics of WBDFs investigated with PAC LV and plant extracts}

The API and HPHT FL was determined at 100 psi and 500 psi differential pressures, respectively, to comprehend the efficiency of HLE and HBLE green additives as fluid loss control agents. Figures 9 and 10 provide the details of these results. The loss of filtrate with both 1.0 and $2.0 \mathrm{~g}$ concentrations of plant extracts and PAC LV was found to be outstanding at 78 and $300{ }^{\circ} \mathrm{F}$. The results showed that PAC LV had almost an identical impact with those of the plant extracts in reducing the API and HPHT FL of the WBDF system, but it exhibited a slightly better sealing property than the plant extracts. The API FL of the base fluid was improved with the HLE, HBLE, and PAC LV by $29.9-32 \%, 31.0-35.1 \%$, and $33.0-37.1 \%$, respectively, from 1.0 to $2.0 \mathrm{~g}$ concentrations. After the heat treatment, it increased in the following pattern; $30.7-31.7 \%, 32.7-33.7 \%$, and $33.7-34.7 \%$ for HLE, HBLE, and PAC LV, respectively. Nevertheless, HLE and HBLE exhibited a better enhancement in the API and HPHT MCT of the WBDFs, as compared to the performance of PAC LV presented in Fig. 10. The MCT was reduced with the introduction of HLE by $30.2 \%, 31.8 \%$ by HBLE, and $23.6 \%$ by PAC LV at $1.0 \mathrm{~g}$ concentration at API conditions. With aging, the HPHT MCT of the base fluid system got reduced by $30.6 \%$ for HLE, $33.4 \%$ for HBLE, and $27.3 \%$ for PAC LV. The decreasing range of the API MCT from
Fig. 9 API and HPHT FL of drilling fluids
Fig. 10 API and HPHT MCT of drilling fluids
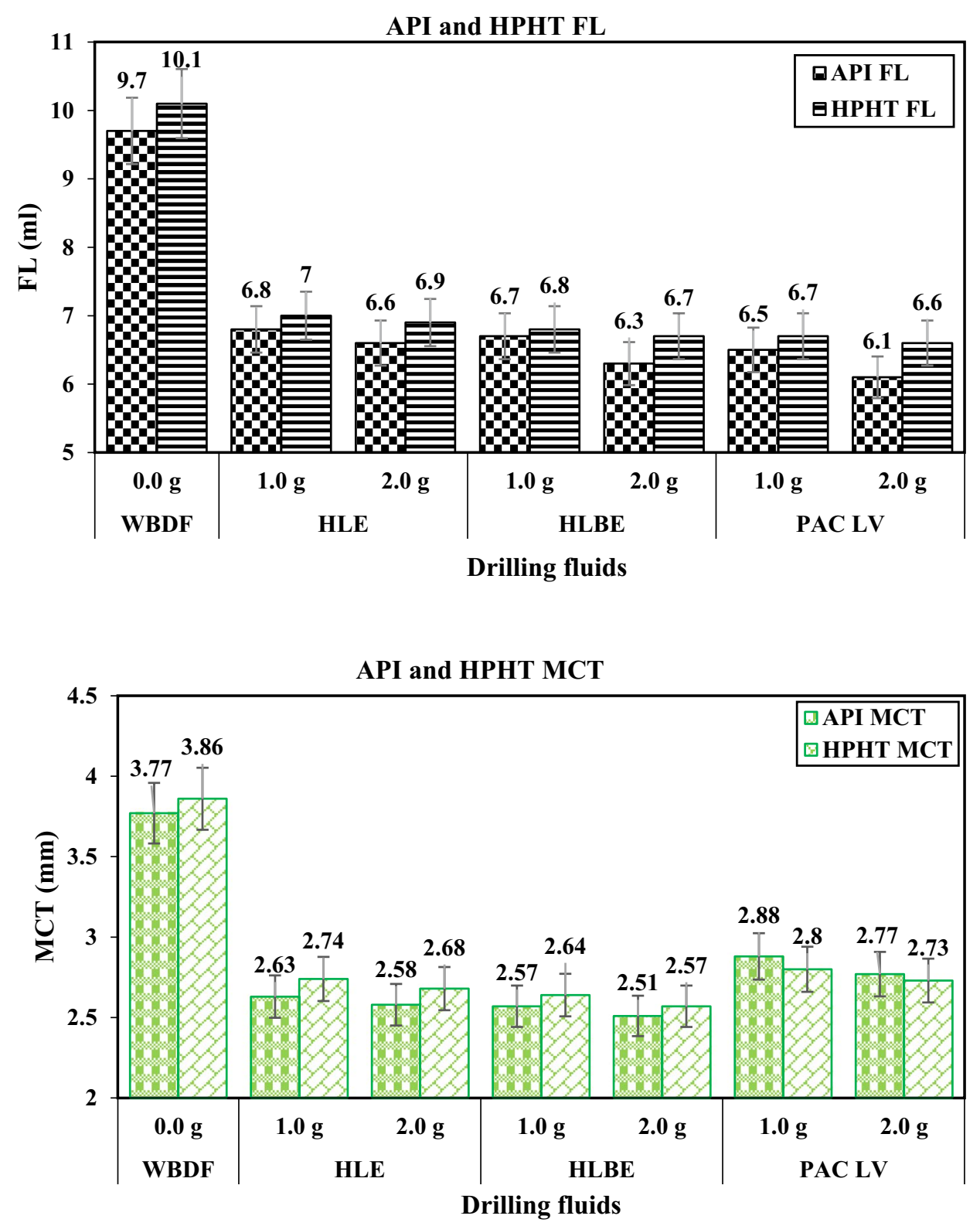
1.0 to $2.0 \mathrm{~g}$ concentrations is as follows: $30.2-31.6 \%$ for HLE, 31.8-33.4\% for HBLE, and 23.6-26.5\% for PAC LV. These results suggest that the plant extracts can be used to improve the mud cake before fortifying the drilled formation with casing to prevent any possible mechanical pipe sticking resulting from dense mud cake (Al-Hameedi et al. 2020; Oseh et al. 2020c, d).

Comparison and evaluation of all the fluids performances showed that after 1.0 and $2.0 \mathrm{~g}$ concentrations of HLE, HBLE, and PAC LV were applied, the rheology and filtration control parameters of the WBDFs improved. Generally, in the WBDFs, the HLE and HBLE played a significant task in the creation of highly compact mud cake, even at lower concentrations. They performed as efficient viscosifiers and filtration control reducers and compared favorably with the PAC LV, which exhibited higher rheological properties, slightly better sealing property, and less cake thickness. It is hoped that these results can provide more insights into the application of HLE and HBLE as low-cost, sustainable, and ecologically benign ingredients for drilling fluids.

\section{Compatibility test and mud cake permeability observations}

The test of compatibility is exceedingly important for the applicability of every drilling fluid additive to assess their interactions with other additives. The data related to compatibility conducted on test fluid A with $25 \mathrm{~g} / \mathrm{L}$ HLE and HBLE are presented in Fig. 11 (for the rheological properties) and Table 6 (for the filtration properties). The rheological properties, filtrate loss volume, and mud cake thickness measured at $221{ }^{\circ} \mathrm{F}$ and $500 \mathrm{psi}$ of the prepared base fluid (A-0) were found to improve after the modification by HLE and HBLE products. The rheological properties of test fluid A-0 were increased by the inclusion of the plant extracts, and these plant extracts also reduced the filtration properties of A- 0 . This is due to the fine-solubility of the green additives in the mud without aggregates. Aggregation can cause a reduction in the viscosity of drilling muds after a long period (Mozaffari et al. 2015, 2017). To precisely account for the changes that occurred because of the incorporation of the green additives, the percentage of increase or decrease as the case may be was calculated by comparing before and after introducing the green additives. Also, the observed trend of Fig. 11 corroborated that A-2 has better improvement impact on the A- 0 properties than A- 1 . These data are consistent with the previous data reported in Tables 4 and 5, wherein the Hibiscus plant exhibited higher rheological properties and lower filtration properties than the Henna product. It was also found from these tables that at a higher temperature of $300^{\circ} \mathrm{F}$, the reduction in the viscosities (AV and YP) of HLE and HBLE was relatively large owing to the fluid's
Fig. 11 Compatibility data of different test fluids with changes in their properties
Table 6 HPHT filtrate volume and mud cake thickness of different test fluids

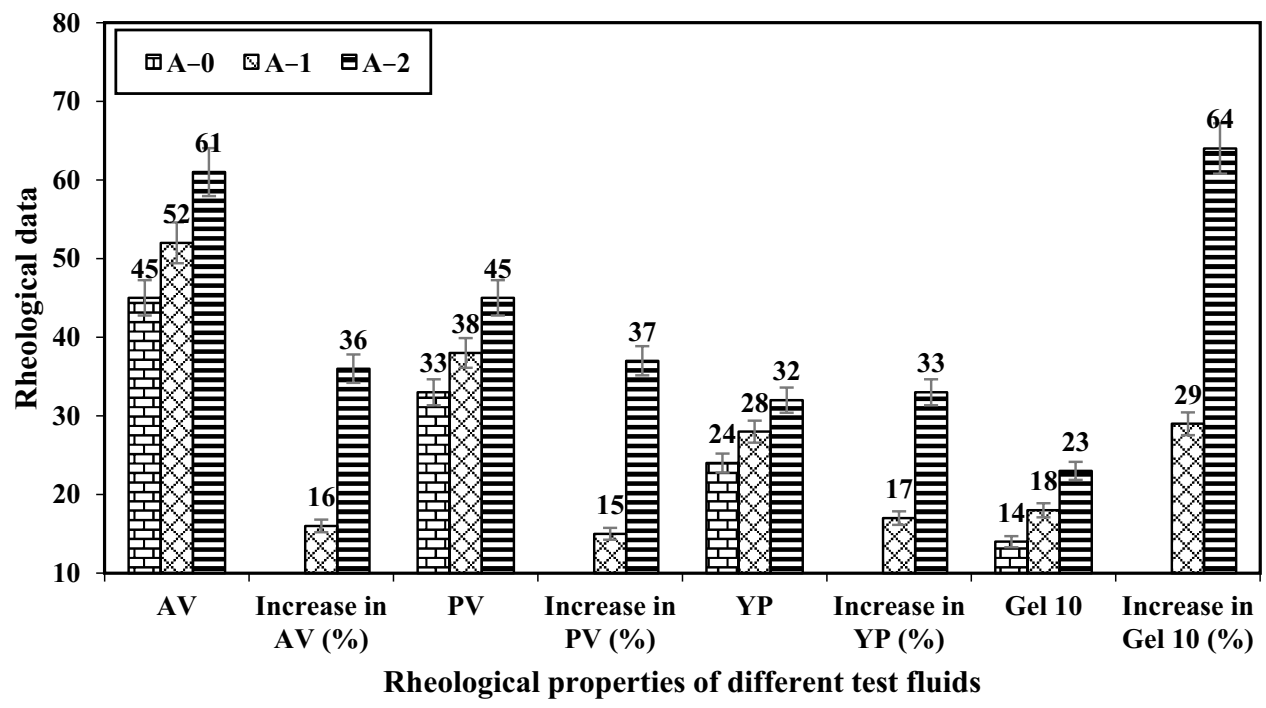

\begin{tabular}{llllll}
\hline Mud system & $\begin{array}{l}\text { Filtrate vol- } \\
\text { ume }(\mathrm{ml})\end{array}$ & $\begin{array}{l}\text { Filtrate change } \\
(\text { decrease } \%)\end{array}$ & $\begin{array}{l}\text { Mud cake } \\
\text { thickness } \\
(\mathrm{mm})\end{array}$ & $\begin{array}{l}\text { Change in mud cake } \\
\text { thickness }(\text { decrease } \%)\end{array}$ & $\begin{array}{l}\text { Cake perme- } \\
\text { ability } \times 10^{-4} \\
(\mathrm{mD})\end{array}$ \\
\hline A-0 & 11.4 & - & 3.86 & - & 2.82 \\
A-1 & 8.8 & 22.8 & 3.42 & 11.4 & 2.31 \\
A-2 & 7.9 & 30.7 & 3.24 & 16.1 & 2.16 \\
\hline
\end{tabular}


aggregation (Mozaffari et al. 2015; 2017). As no substantial changes were observed with these data (Fig. 11 and Table 6) and those reported in Tables 4 and 5, the compatibility of common WBDF additives with HLE and HBLE was completely obvious.

Table 6 summarizes the filtration behavior of A-0 (base fluid), A-1 (HLE), and A-2 (HBLE) mud systems under the HPHT conditions. It can be observed that the change in the filtrate volume of $\mathrm{A}-0$ with $25 \mathrm{~g} / \mathrm{L}$ of HLE and HBLE products decreased by $8.8 \%$ with $\mathrm{A}-1$ and $7.9 \%$ with $\mathrm{A}-2$. In the same vein, the thickness of the mud cake of the A-0 was decreased with the inclusion of the two green additives by $11.4 \%$ (with HLE) and $16.1 \%$ (with HBLE). The permeability of the mud cake determined as presented in Table 6 displayed a higher permeability for the Henna extracts mud system compared to the Hibiscus leaf extracts but the highest cake permeability was observed in the base fluid. Furthermore, observation of Fig. 12 revealed that the cake thickness of both the HLE and HBLE samples was low and nonerodible with lower permeabilities compared to the base test fluid. Given these data, it can be concluded that the $25 \mathrm{~g} / \mathrm{L}$ of the plant extracts is compatible with the common WBDF additives and these cake permeabilities are not high to cause damage to the drilled formation.

\section{Linear swelling test observation of sodium bentonite}

The linear swelling of sodium bentonite exposed to distilled water and different concentrations of HLE and HBLE aqueous solution at a temperature of $78^{\circ} \mathrm{F}$ was examined. The results are shown in Fig. 13. According to Fig. 13, swelling curves of all the mud systems exhibited a liketrend with sharp increases in the first- $6 \mathrm{~h}$, which is similar to the swelling character reported by Moslemizadeh et al. (2015) and Darjani et al. $(2017,2019)$ for montmorillonite in aqueous systems. The sodium bentonite in distilled water was found to follow a constant swelling character within the entire test time of $24 \mathrm{~h}$ with the highest swelling level compared to other mud systems. The swelling behavior of the sodium bentonite in any concentration of HLE and HBLE was observed to be considerably lower than in distilled water at each period and after the test completion

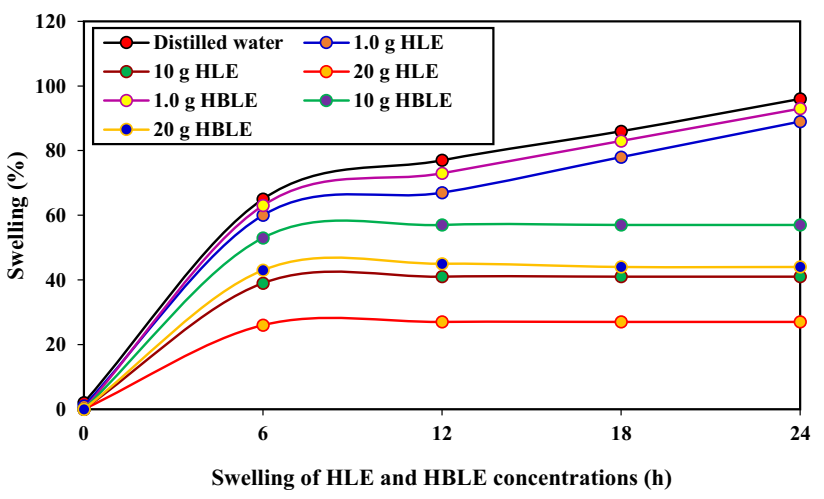

Fig. 13 Swelling data of sodium bentonite in distilled water exposed to different concentrations of HLE and HBLE solutions at $78^{\circ} \mathrm{F}$

for $24 \mathrm{~h}$. This translates the attractively benefiting influence that the locally derived green products had on the swelling behavior of sodium bentonite. At the lowest concentration $(1.0 \mathrm{~g})$ of each of HLE and HBLE in the distilled water, the sodium bentonite still carries on swelling during the entire test period even if its swelling curve is lower than that in distilled water alone. It was also observed that the introduction of the HLE product in the distilled water displays a higher reduction in the swelling rate of the sodium bentonite at all concentrations than the HBLE product. This interprets the superiority of the HLE in inhibiting the swelling behavior of sodium bentonite over the HBLE product. However, the final regime in which the swelling rate of the sodium bentonite with these two products approaches zero was never realized. In contrast, the swelling curves for higher concentrations (10 and $20 \mathrm{~g}$ ) of HLE and HBLE show the final regime after about $18 \mathrm{~h}$.

\section{Conclusions}

In the current study, an all-inclusive set of tests was conducted on a complex WBDF system with different concentrations of two locally derived green additives (Henna leaf and Hibiscus leaf extracts). The results of these plant extracts at 1.0 and $2.0 \mathrm{~g}$ concentrations were compared with that of industrial-based PAC LV to investigate their
Fig. 12 HPHT mud cake filtrations for different test fluids

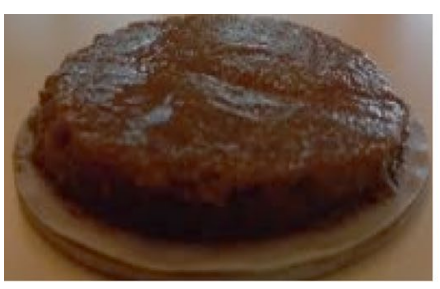

$\mathrm{A}-0\left(\mathrm{~K}=\mathbf{2 . 8 2} \times 10^{-4} \mathrm{mD}\right)$

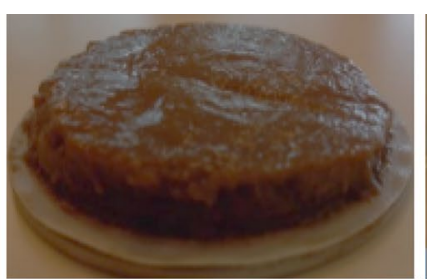

$\mathrm{A}-1\left(\mathrm{~K}=2.31 \times 10^{-4} \mathrm{mD}\right)$

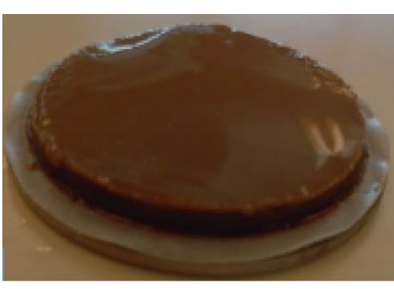

$\mathrm{A}-2\left(\mathrm{~K}=2.16 \times 10^{-4} \mathrm{mD}\right)$ 
impacts on the rheological and filtration properties of the WBDF system. Furthermore, swelling inhibitive behavior of sodium bentonite powder with the green additives and the compatibility of these green additives with other additives in the WBDF system was examined. The following conclusions were drawn based on the research goals and the results reached:

1. The inclusion of higher concentrations (between 10 and $40 \mathrm{~g}$ ) of HLE and HBLE largely enhanced the rheological and filtration parameters of the WBDFs. With lower concentrations (1.0 and $2.0 \mathrm{~g}$ ) in the WBDFs, the influence of HLE and HBLE was relatively less than that of PAC LV, which showed higher mud's properties.

2. Also, the gels of HLE and HBLE at 1.0 and $2.0 \mathrm{~g}$ concentrations showed excellent suspension capacity as the variation between the initial and 10 min gels was not more than $5.0 \mathrm{lb} / 100 \mathrm{ft}^{2}$, unlike that of PAC LV that indicated high and progressive gel structure that exceeded $10 \mathrm{lb} / 100 \mathrm{ft}^{2}$. This variation can affect drilling operations drastically.

3. The test of compatibility confirmed that the plant extracts are compatible with the common WBDF additives and had an affirmative influence on the filtrate loss volume.

4. The dynamic linear swelling test verified that HLE and HBLE reduced the swelled volume of the evaluated sodium bentonite. To recap, the studied HLE and HBLE demonstrated enhancing effect in the properties of the WBDF system making them suitable agents for WBDF.

Acknowledgments The authors would like to thank the research management center of the Universiti Teknologi Malaysia (UTM) and the Malaysia Ministry of Higher Education (MOHE) for the support they have given through the research grant (vote no. 4F437 FRGS/1/2014/ TK06/UTM/02/12).

\section{Compliance with ethical standards}

Conflict of interest On behalf of all the authors, the corresponding author states that there is no conflict of interest.

Open Access This article is licensed under a Creative Commons Attribution 4.0 International License, which permits use, sharing, adaptation, distribution and reproduction in any medium or format, as long as you give appropriate credit to the original author(s) and the source, provide a link to the Creative Commons licence, and indicate if changes were made. The images or other third party material in this article are included in the article's Creative Commons licence, unless indicated otherwise in a credit line to the material. If material is not included in the article's Creative Commons licence and your intended use is not permitted by statutory regulation or exceeds the permitted use, you will need to obtain permission directly from the copyright holder. To view a copy of this licence, visit http://creativecommons.org/licenses/by/4.0/.

\section{References}

Abdollahi R, Shadizadeh SR (2012) Effect of acid additives on anticorrosive property of henna in regular mud acid. Sci Iran 19:1665-1671

Aftab A, Ismail AR, Khokhar S, Ibupoto ZH (2016) Novel zinc oxide nanoparticles deposited acrylamide composite used for enhancing the performance of water-based drilling fluids at elevated temperature conditions. J Pet Sci Eng 146:1142-1157

Al-Hameedi ATT, Alkinani HH, Dunn-Norman S, Alashwak NA, Alshammari AF, Alkhamis MM, Alsaba MT (2019a) Environmental friendly drilling fluid additives: can food waste products be used as thinners and fluid loss control agents for drilling fluid? Soc Pet Eng. https://doi.org/10.2118/195410-ms

Al-Hameedi ATT, Alkinani HH, Dunn-Norman S, Albazzaz HW, Alkhamis MM (2019b) Insights into eco-friendly and conventional drilling additives: applications, cost analysis, health, safety, and environmental considerations. Soc Pet Eng. https:// doi.org/10.2118/195398-ms

Al-Hameedi ATT, Alkinani HH, Norman SD, Al-Alwani MA, Alshammari AF, Alkhamis MM, Mutar RA, Al-Bazzaz WH (2020) Experimental investigation of environmentally friendly drilling fluid additives (mandarin peels powder) to substitute the conventional chemicals used in water-based drilling fluid. J Pet Explor Prod Technol 10:407-417. https://doi.org/10.1007/s1320 2-019-0725-7

Al-Sehaibani H (2002) Evaluation of extracts of henna leaves as environmentally friendly corrosion inhibitors for metals. Mater Werkst 31:1060-1063

Amani M, AL-Jubouri M, Shadravan A (2012) Comparative study of using oil-based mud versus water-based mud in HPHT fields. Adv Pet Explor Dev 4(2):18-27

American Petroleum Institute 13B-1 (2017) Recommended practice for field testing water-based drilling fluids, 5th ed, pp 1-121

Annis MR, Smith V (1996) Drilling fluids technology. Exxon Company, Irving

Balestrini A, Maas A, Seheult M, Morton EK (2009) Advances in API/ISO standard grade purified poly-anionic cellulose (PAC) and drilling grade xanthan gum (XG) test procedure and specifications definition. Soc Pet Eng. https://doi.org/10.2118/11997 3-ms

Caenn R, Darley HCH, Gray GR (2017) Introduction to drilling fluids. Composition and properties of drilling and completion fluids, 7 th edn. Gulf Professional Publishing, New York, pp 1-748. ISBN 978-0-12-804751-4

Choo KY, Bai K (2015) Effects of bentonite concentration and solution $\mathrm{pH}$ on the rheological properties and long-term stabilities of bentonite suspensions. Appl Clay Sci 108:82-190

Darjani S, Koplik J, Pauchard V (2017) Extracting the equation of state of lattice gases from random sequential adsorption simulations by means of the Gibbs adsorption isotherm. Phys Rev E 96(5-1):052803. https://doi.org/10.1103/PhysRevE.96.052803

Darjani S, Koplik J, Banerjee S, Pauchard V (2019) Liquid-hexatic-solid phase transition of a hard-core lattice gas with third neighbor exclusion. J Chem Phys 151(10):104702. https://doi. org/10.1063/1.5123231

Elochukwu H, Gholami R, Dol SS (2017) An approach to improve the cuttings carrying capacity of nanosilica based muds. J Pet Sci Eng 152:309-316

Fattah KA, Lashin A (2016) Investigation of mud density and weighting materials effect on drilling fluid filter cake properties and formation damage. J Afr Earth Sci 117:345-357. https://doi. org/10.1016/j.jafrearsci.2016.02.003

Fujii R (2017) Hundred years' history of challenge to shale inhibition. J Jpn Assoc Pet Technol 82(5):332-345

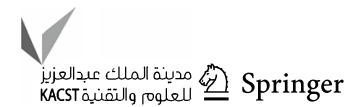


Gamal H, Elkatatny S, Basfar S, Al-Majed A (2019) Effect of pH on rheological and filtration properties of water-based drilling fluid based on bentonite. Sustainability 11(23):6714. https://doi. org/10.3390/su11236714

Gozubuyuk GS, Aktas E, Yigit N (2014) An ancient plant lawsonia inermis (Henna): determination of in vitro antifungal activity against dermatophytes species. J Do Mycol Medicale. https://doi. org/10.1016/j.mycmed.2014.07.002

Iheagwara $\mathrm{O}$ (2015) Comparative analysis of the use of banana peels and $\mathrm{NaOH}$ in $\mathrm{pH}$ control in Nigerian clays. J Niger Assoc Math Phys 30:197-202

Ismail AR, Jaafar MZ, Wan R, Wan S, Ariff R (2015) Shale swelling mitigation in water-based drilling fluids with amine additives. In: 8th International conference on geological and geo-resources engineering, Penang, Malaysia 35:23-31

Ismail AR, Mohd Norddin MNA, Latefi NAS, Oseh JO, Issham I, Gbadamosi AO, Agi A (2019) Evaluation of a naturally derived tannin extracts biopolymer additive in drilling muds for hightemperature well applications. J Pet Explor Prod Technol 1:1-17. https://doi.org/10.1007/s13202-019-0717-7

Kelessidis VC (2017) Yield stress of bentonite dispersions. Rheol Open Access 1(1):1-12

Luz RCS, Fagundes FP, Balaban RC (2017) Water-based drilling fluids: the contribution of xanthan gum and carboxyl methyl cellulose on filtration control. Soc Pet Eng J 36(71):2365-2373

Moslemizadeh A, Shadizadeh SR, Moomenie M (2015) Experimental investigation of the effect of henna extract on the swelling of sodium bentonite in aqueous solution. Appl Clay Sci 105:78-88

Moslemizadeh A, Shadizadeh SR, Moomenie M (2016) A natural dye in water-based drilling fluid: swelling inhibitive characteristics and side effects. Petroleum 3:1-12

Mozaffari S, Tchoukov P, Atias J, Czarnecki J, Nazemifard N (2015) Effect of asphaltene aggregation on rheological properties of diluted athabasca bitumen. Energy Fuels 29(9):5595-5599. https ://doi.org/10.1021/acs.energyfuels.5b00918

Mozaffari S, Choukov P, Mozaffari A, Atias J, Czarnecki J, Nazemifard N (2017) Capillary driven flow in nano channels-application to heavy oil rheology studies. Colloids Surfaces A: Physicochem Eng Aspects 513:178-187. https://doi.org/10.1016/j.colsu rfa.2016.10.038

Nanthagopal K, Ashok B, Garnepudi RS, Tarun KR, Dhinesh B (2019) Investigation on diethyl ether as an additive with Calophyllum inophyllum biodiesel for CI engine application. Energy Convers Manag 179:104-113

Obi FO, Usenu IA, Osayande JO (1998) Prevention of CCL4 induced hepatotocxicity in the rat by $\mathrm{H}$. Rosa Sinensis anthocyanin extract administered in ethanol. Toxicol 131:93-98

Omotioma M, Ejikeme PCN (2014) Comparative analysis of the effects of cashew and mango extracts on the rheological properties of water based mud. Int J Eng Res Appl 4(10):56-61

Oseh JO, Gbadamosi AO, Ogunyemi A, Omotara OO (2018) Transports of different cuttings sizes in a wellbore using henna and lignite materials. J Eng Res Dev (AJERD) 3:351-365

Oseh JO, Mohd Norddin MNA, Ismail I, Gbadamosi AO, Agi A, Mohammed HN (2019a) A novel approach to enhance rheological and filtration properties of water-based mud using polypropylene-silica nanocomposite. J Pet Sci Eng 181(106264):1-25. https://doi.org/10.1016/j.petrol.2019.106264

Oseh JO, Mohd Norddin MNA, Ismail I, Ismail AR, Gbadamosi AO, Agi A (2019b) Effect of the surface charge of entrapped polypropylene at nanosilica-composite on cuttings transport capacity of water-based muds. Appl Nanosci 10(1):61-82

Oseh JO, Mohd Norddin MNA, Ismail I, Ismail AR, Gbadamosi AO, Agi A, Ogiriki SO (2019c) Investigating almond seed oil as potential biodiesel-based drilling mud. J Pet Sci Eng 181(106201):1-16
Oseh JO, Norddin MNA, Farooq F, Ismail I, Ismail AR, Gbadamosi AO, Agi A (2019d) Experimental investigation of the effect of henna leaf extracts on cuttings transportation in highly deviated and horizontal wells. J Pet Explor Prod Technol. https://doi. org/10.1007/s13202-019-0631-z

Oseh JO, Mohd Norddin MNA, Ismail I, Gbadamosi AO, Agi A, Ismail AR (2020a) Experimental investigation of cuttings transportation in deviated and horizontal wellbores using polypropylene-nanosilica composite drilling mud. J Pet Sci Eng 106958:1-24. https ://doi.org/10.1016/j.petrol.2020.106958

Oseh JO, Mohd Norddin MNA, Muhamad HN, Ismail I, Gbadamosi AO, Agi A, Ismail AR, Blkoor SO (2020b) Influence of (3-Aminopropyl) triethoxysilane on entrapped polypropylene at nanosilica composite for shale swelling and hydration inhibition. J Pet Sci Eng 194(107560):1-16. https://doi.org/10.1016/j.petro 1.2020 .107560

Oseh JO, Norddin MNAM, Ismail I, Gbadamosi AO, Agi A, Ismail AR (2020c) Study of cuttings lifting with different annular velocities using partially hydrolyzed polyacrylamide and enriched polypropylene-nanosilica composite in deviated and horizontal wells. Appl Nanosci 10(3):971-993

Oseh JO, Norddin MNAM, Ismail I, Gbadamosi AO, Agi A, Ismail AR, Manoger P, Ravichandran K (2020d) Enhanced cuttings transport efficiency of water-based muds using (3-Aminopropyl) triethoxysilane on polypropylene-nanosilica composite. Arab J Chem. https://doi.org/10.1016/j.arabjc.2020.07.004

Ostovari A, Hoseinieh S, Peikari M, Shadizadeh SR, Hashemi S (2009) Corrosion inhibition of mild steel in $1 \mathrm{M} \mathrm{HCl}$ solution by henna extract: a comparative study of the inhibition by henna and its constituents (Lawsone, Gallic acid, $\alpha$-d-glucose and Tannic acid). Corros Sci 51:1935-1949

Saboori R, Sabbaghi S, Kalantarias A, Mowla D (2018) Improvement in filtration properties of water-based drilling fluid by nanocarboxymethyl cellulose/polystyrene core-shell nanocomposite. J Pet Explor Prod Technol 8:445-454

Samaravati R, Abdullah NK, Hussain SA, Awang Biak DR (2014) The prospect of utilizing a cassava derivative (Fufu) as a fluid loss agent in water based drilling muds. Int J Chem Eng Appl

Sayindla S, Lund B, Ytrehus JD, Saasen A (2017) Hole-cleaning performance comparison of oil-based and water-based drilling fluids. J Pet Sci Eng 159:49-57

Sharada B, Basavaraj BV, Bharath S, Deveswaran R, Madhavan V (2012) Sustained release matrix tables of indomethacin using hibiscus rosa sinensis as release retardant. Der Pharmacia Lettr 4:227-233

Thomas DC (1982) Thermal stability of starch- and carboxyl methyl cellulose- based polymers used in drilling fluids. Soc Pet Eng. https://doi.org/10.2118/8463-pa

Wei WC (2013) Nano Corn Starch Application for Water Based Mud Properties and Performance Improvement, Master of Science. Thesis. Universiti Teknologi Malaysia: Malaysia

Xu J, Qiu Z, Zhao X, Zhong H, Li G, Huang W (2018) Synthesis and characterization of shale stabilizer based on polyethylene glycol grafted nano-silica composite in water-based drilling fluids. J Pet Sci Eng 163:371-377

Zhong H, Qiu W, Huang W, Cao J (2011) Shale inhibitive properties of polyether diamine in water-based drilling fluid. J Pet Sci Eng 78:510-515

Zhong H, Shen G, Qiu Z, Lin Y, Fan L, Xing X, Li J (2019) Minimizing the HTHP filtration loss of oil-based drilling fluid with swellable polymer microspheres. J Petrol Sci Eng 172:411-424

Publisher's Note Springer Nature remains neutral with regard to jurisdictional claims in published maps and institutional affiliations. 